\title{
"Too many betas do not spoil the broth": the role of beta brain oscillations in language processing
}

\author{
Sabine Weiss ${ }^{1,2 *}$ and Horst M. Mueller ${ }^{1,2,3}$ \\ 'Center of Excellence "Cognitive Interaction Technology," (CITEC), Bielefeld University, Bielefeld, Germany \\ ${ }^{2}$ Experimental Neurolinguistics Group, Bielefeld University, Bielefeld, Germany \\ ${ }^{3}$ Collaborative Research Center "Alignment in Communication" (SFB 673), Bielefeld University, Bielefeld, Germany
}

\section{Edited by:}

Lucia Melloni, Max Planck Institute

for Brain Research, Germany

\section{Reviewed by:}

Olaf Hauk, Medical Research Council Cognition and Brain Sciences Unit, UK Luc H. Arnal, New York University, USA

\section{*Correspondence:}

Sabine Weiss, Experimental Neurolinguistics Group, Center of Excellence "Cognitive Interaction Technology," Bielefeld University, P.O Box 100131, Bielefeld 33502, Germany.

e-mail:sabine.weiss@uni-bielefeld.de
Over the past 20 years, brain oscillations have proven to be a gateway to the understanding of cognitive processes. It has been shown that different neurocognitive aspects of language processing are associated with brain oscillations at various frequencies. Frequencies in the beta range $(13-30 \mathrm{~Hz})$ turned out to be particularly important with respect to cognitive and linguistic manipulations during language processing. Beta activity has been involved in higher-order linguistic functions such as the discrimination of word categories and the retrieval of action semantics as well as semantic memory, and syntactic binding processes, which support meaning construction during sentence processing. From a neurophysiological point of view, the important role of the beta frequencies for such a complex cognitive task as language processing seems reasonable. Experimental evidence suggests that frequencies in the beta range are ideal for maintaining and preserving the activity of neuronal assemblies over time. In particular, recent computational and experimental evidence suggest that beta frequencies are important for linking past and present input and the detection of novelty of stimuli, which are essential processes for language perception as well as production. In addition, the beta frequency's role in the formation of cell assemblies underlying short-term memory seems indispensable for language analysis. Probably the most important point is the well-known relation of beta oscillations with motor processes. It can be speculated that beta activities reflect the close relationship between language comprehension and motor functions, which is one of the core claims of current theories on embodied cognition. In this article, the importance of beta oscillations for language processing is reviewed based both on findings in psychophysiological and neurophysiological literature.

Keywords: brain oscillations, beta, frequency, language, power, coherence

\section{INTRODUCTION}

The brain generates a broad range of rhythms of different frequencies, which are commonly associated with different physiological and cognitive functions. It is well accepted that these different oscillation frequencies are associated with a divergent underlying physiology being generated by at least 10 different mechanisms and the cooperative work of many neuronal structures (Buzsáki, 2006). The relation between brain anatomy and oscillatory patterns allows the brain to operate at multiple temporal and spatial scales. Because of that, activity within distinct oscillations can contribute diversely to the formation of neuronal assemblies, which underlie neurocognitive processes and, in particular, different aspects of linguistic processing (Weiss and Mueller, 2003; Bastiaansen and Hagoort, 2006). However, the exact role different oscillations are playing in cognition and language is largely unknown and still a topic of debate.

Oscillatory activity allows activated neuronal groups in distant cortical regions to become temporarily linked ("synchronized"; von der Malsburg and Schneider, 1986; Gray et al., 1989; Engel et al., 2001; Singer, 2009). Oscillations of neuronal assemblies rhythmically open and close the communication window between groups for a given signal frequency. This mechanism allows for effective communication because the communication windows of both groups are open simultaneously and explains why synchronization (no or small phase shift) can be observed over long distances despite long conduction delays (Fries, 2005). Usually, the brain oscillations are subdivided into five main frequency bands: delta $(0.5-3.5 \mathrm{~Hz})$, theta $(4-7 \mathrm{~Hz})$, alpha $(8-12 \mathrm{~Hz})$, beta $(13-30 \mathrm{~Hz})$, and gamma $(>30 \mathrm{~Hz})$ and often, these frequency bands are further subdivided into narrower ranges (e.g., beta1: 13$18 \mathrm{~Hz}$; beta2: $19-25 \mathrm{~Hz}$; beta3: $26-30 \mathrm{~Hz}$ ). The frequency of such oscillations determines the temporal windows of processing and indirectly the size of the neuronal structures involved (von Stein and Sarnthein, 2000; Buzsáki, 2006). In a wider time window, more neurons can be recruited from larger brain areas because synaptic and axonal conductance delays are less limiting. Hence, the spatial extent of synchrony is much larger for slow rhythms. Slow oscillations can involve many neuronal groups across widely distributed brain areas, whereas fast oscillations are predestinated for local information processing due to their shorter time window 
for information exchange (Nunez, 2000; Buzsáki and Draguhn, 2004).

In a simplified computer model using only few simulated cells it was shown that, for instance, beta $(19-29 \mathrm{~Hz})$ and gamma $(30-70 \mathrm{~Hz})$ frequencies employ different dynamical mechanisms based on different ionic currents to synchronize (e.g., Kopell et al., 2000, 2010). Increases in conduction delays between the cells plus increases in the strength of synapses between excitatory cells effect a transition of the network activity from gamma to beta. That being the case, it turned out that coupling across distances lowers the frequency of the coupled rhythm (Kopell et al., 2000). Consequently, it was concluded that beta frequencies are able to synchronize over long conduction delays ( $>20 \mathrm{~ms}$ ), which corresponds to signals traveling long distances in the brain, whereas gamma frequencies are used for relatively local computations and support robust synchronization for conduction delays up to 8-10 ms. However, not only conduction delays but also other factors determine the frequency of oscillation such as the number of interacting cortical neurons and/or the modulatory transmitters released from subcortical systems or the frequency of local oscillations (Siegel et al., 2012).

Therefore, distant brain areas, which have long axonal conduction delays and are connected predominantly via the gray matter, are more likely to synchronize in beta frequencies. In contrast, gamma oscillations are found between regions that lie either closely together or have connections via the white matter and thus have short interconnection delays (Kopell et al., 2000; Buzsáki, 2006). For instance, gamma-band oscillations seem to be involved in the local encoding of cognitive information, whereas diverse oscillations frequently involving the beta frequency range are concerned with integrative functions across long distances (von Stein and Sarnthein, 2000; Weiss and Mueller, 2003; Weiss et al., 2005; Donner and Siegel, 2011). Thus, partly dependent on the actual distance of information transfer, different frequencies may be associated with the same or different cognitive activities. This may be a reason for the heterogeneous results concerning the interpretation of frequency-related cognitive operations. Another reason deals with the difficulty to assign a single cognitive function to a single oscillatory activity. Often there is a complex (maybe non-linear) interplay and dynamic interaction between different frequency bands and cognitive functions. Diverse rhythms or variations of a rhythm can support different components of a cognitive act, with multiple rhythms potentially playing multiple roles (Başar et al., 1999; Klimesch, 1999; von Stein and Sarnthein, 2000; Weiss and Mueller, 2003; Jensen and Colgin, 2007; Kopell et al., 2010).

According to the neurophysiological and computational evidence referred to above, oscillations in the beta frequency band $(13-30 \mathrm{~Hz})$ are particularly suited for functional roles in language processing. Aside from having a role in motor processing, beta frequencies are associated with various cognitive operations and certain aspects of language processing. Experimental evidence supporting this finding will be provided in Section "Experimental Evidence on Beta Oscillations and Language." Studies have evidenced that beta frequencies may be important "carriers" for the complex linguistic information required for language processing, which involves activity from of a huge set of large-scale neuronal networks widely distributed across the brain. The following section will mainly deal with the relationship between findings in the beta frequency band and language processes and their neurocognitive interpretation.

\section{EXPERIMENTAL EVIDENCE ON BETA OSCILLATIONS AND LANGUAGE}

In contrast to numerous studies on the relation of theta, alpha, and gamma EEG frequencies associated with different aspects of language processing, there exist relatively few studies with respect to beta oscillations and language. The following sections review studies in which beta frequencies play a specific and important role in language tasks and are only partly accompanied by findings in other frequency bands. Moreover, the relation of beta changes to different cognitive operations underlying language processing such as (1) action semantics, (2) expectancy violation and attention, (3) binding, and (4) memory will be highlighted. This subdivision is taken up again and summarized in Section "Beta Oscillations and Language: A Synopsis."

Generally, studies on either healthy participants or patients have dealt with beta power changes during language processing (see also Table 1) and only very few reported on EEG coherence changes. Since power and coherence findings have to be interpreted differently (see Neuronal Scale) the following paragraphs are partly separated into studies either investigating mainly power or mainly coherence changes related to language tasks. The majority of studies on the relation between beta power and language processing report decrease of power; and only few report increases of power with respect to task manipulation. Both findings on beta decreases and increases associated with different language tasks will be reviewed in the following sections (see Table 1).

\section{ACTION SEMANTICS (MOTOR-RELATED BETA)}

From a classical point of view, beta oscillations are mainly related to motor processes. Intrinsic beta oscillations are recorded predominantly at the somatomotor and premotor cortex but have also been detected in the basal ganglia and the cerebellum, both of are involved not only in motor but also in cognitive functions. A large majority of studies have shown that synchronized beta frequency oscillations are involved in the maintenance of persistent contractions of arm- and hand muscles in humans (e.g., Pfurtscheller et al., 1996) as well as in non-human primates (Baker, 2007). Desynchronization of the lower beta band $(16-24 \mathrm{~Hz})$ over sensorimotor areas has been interpreted as being related to active and passive movements and to motor imagery (Neuper et al., 2006; de Lange et al., 2008) including even the observation of another person's movements (Hari et al., 1998; Babiloni et al., 2002; Jarvelainen et al., 2004).

Therefore, a desynchronization of beta power (mainly over left frontal and premotor cortex) has been repeatedly found during overt and covert word generation, and preparation of an itemrelated motor reaction. Motor-related changes in the beta range can be obtained both during the actual activation of the motor system (e.g., verb generation) and its secondary involvement induced by relevant language stimuli (e.g., action verbs).

For example, during a letter fluency task, where participants read a letter and had to generate as many words as possible, strong 
Table 1 | Studies on beta power changes related to language processing (in chronological order).

\begin{tabular}{|c|c|c|c|c|c|}
\hline $\begin{array}{l}\text { Authors (in } \\
\text { chronological } \\
\text { order) }\end{array}$ & $\begin{array}{l}\text { Beta } \\
\text { power } \\
\text { change }\end{array}$ & Task and stimuli & $\begin{array}{l}\text { Frequency } \\
\text { range }(\mathrm{Hz})\end{array}$ & $\begin{array}{l}\text { Time after word onset } \\
\text { and topography }\end{array}$ & Interpretation \\
\hline $\begin{array}{l}\text { Klimesch et al. } \\
\text { (2001) }\end{array}$ & & $\begin{array}{l}\text { Visual } \\
\text { Meaningful words vs. } \\
\text { pseudowords } \\
\text { Dyslexics and controls }\end{array}$ & $\sim 14-16$ & Left frontal, left parietal & Grapheme-phoneme encoding \\
\hline Singh et al. (2002) & & $\begin{array}{l}\text { Visual } \\
\text { Word generation } \\
\text { Letter fluency task }\end{array}$ & $15-25$ & $\begin{array}{l}\text { Left prefrontal and inferior } \\
\text { frontal }\end{array}$ & Increase of neuronal activation \\
\hline $\begin{array}{l}\text { Bastiaansen et al. } \\
\text { (2005) }\end{array}$ & & $\begin{array}{l}\text { Visual } \\
\text { Open class vs. closed class } \\
\text { words }\end{array}$ & $16-21$ & $\begin{array}{l}200-500 \mathrm{~ms} \\
\text { Left and right } \\
\text { occipito-temporal }\end{array}$ & $\begin{array}{l}\text { Higher attention to more important } \\
\text { words }\end{array}$ \\
\hline $\begin{array}{l}\text { Davidson and } \\
\text { Indefrey (2007) }\end{array}$ & & $\begin{array}{l}\text { Visual } \\
\text { Non-grammatical vs. } \\
\text { grammatical sentences }\end{array}$ & $14-30$ & $500-900 \mathrm{~ms}$ & Attention to grammatical violation \\
\hline $\begin{array}{l}\text { Grabner et al. } \\
(2007)\end{array}$ & & $\begin{array}{l}\text { Visual } \\
\text { High-frequency vs. } \\
\text { low-frequency words } \\
\text { Translation of words from } \\
\text { English to German }\end{array}$ & $20-30$ & $400 \mathrm{~ms}$ & $\begin{array}{l}\text { Stronger motor preparation for } \\
\text { high-frequency words }\end{array}$ \\
\hline $\begin{array}{l}\text { Hirata et al. } \\
\text { (2007) }\end{array}$ & & $\begin{array}{l}\text { Visual } \\
\text { Emotional vs. emotionless } \\
\text { nouns }\end{array}$ & $13-30$ & $\begin{array}{l}\text { Left inf. and mid frontal, } \\
\text { Anterior cingulate cortex } \\
\text { Right prefrontal }\end{array}$ & Emotional processing \\
\hline $\begin{array}{l}\text { Fisher et al. } \\
\text { (2008) }\end{array}$ & & $\begin{array}{l}\text { Auditory } \\
\text { Verb generation }\end{array}$ & $\begin{array}{l}15-25 \\
12-20\end{array}$ & $\begin{array}{l}250-500 \mathrm{~ms} \\
\text { Left inf. frontal } \\
\text { Right frontal and sup. } \\
\text { parietal }\end{array}$ & $\begin{array}{l}\text { Language lateralization, neuronal } \\
\text { activation }\end{array}$ \\
\hline $\begin{array}{l}\text { Kim and Chung } \\
\text { (2008) }\end{array}$ & & $\begin{array}{l}\text { Auditory } \\
\text { Deviant vs. standard words } \\
\text { Oddball paradigm in epilepsy } \\
\text { patients }\end{array}$ & $13-25$ & $\begin{array}{l}\text { Left inf. frontal and post. } \\
\text { sup. temporal }\end{array}$ & Occurrence of unexpected stimuli \\
\hline $\begin{array}{l}\text { Hanslmayr et al. } \\
\text { (2009) }\end{array}$ & & $\begin{array}{l}\text { Visual } \\
\text { Remembered vs. not } \\
\text { remembered nouns } \\
\text { Deep semantic encoding }\end{array}$ & $12-20$ & $\begin{array}{l}500-1500 \text { ms left frontal } \\
\text { and parietal }\end{array}$ & $\begin{array}{l}\text { Semantic encoding of episodic } \\
\text { memories }\end{array}$ \\
\hline $\begin{array}{l}\text { Shahin et al. } \\
\text { (2009) }\end{array}$ & & $\begin{array}{l}\text { Auditory } \\
\text { Semantic vs. voice analysis } \\
\text { Oddball paradigm }\end{array}$ & $\begin{array}{l}13-20 \\
25-30\end{array}$ & $\begin{array}{l}\text { 150-600 ms, posterior } \\
\text { electrodes } \\
\text { Fronto-central }\end{array}$ & $\begin{array}{l}\text { 13-20 Hz: attention, motor } \\
\text { preparation, memory search } \\
25-30 \mathrm{~Hz} \text { : template matching in } \\
\text { auditory memory }\end{array}$ \\
\hline $\begin{array}{l}\text { Bastiaansen et al. } \\
\text { (2010) }\end{array}$ & & $\begin{array}{l}\text { Visual } \\
\text { correct sentences vs. word } \\
\text { category violation }\end{array}$ & $13-18$ & $\begin{array}{l}\text { Left frontal, left and right } \\
\text { parietal }\end{array}$ & $\begin{array}{l}\text { Maintenance of lexico-syntactic } \\
\text { information over time }\end{array}$ \\
\hline
\end{tabular}


Table 1 | Continued

\begin{tabular}{|c|c|c|c|c|c|}
\hline $\begin{array}{l}\text { Authors (in } \\
\text { chronological } \\
\text { order) }\end{array}$ & $\begin{array}{l}\text { Beta } \\
\text { power } \\
\text { change }\end{array}$ & Task and stimuli & $\begin{array}{l}\text { Frequency } \\
\text { range }(\mathrm{Hz})\end{array}$ & $\begin{array}{l}\text { Time after word onset } \\
\text { and topography }\end{array}$ & Interpretation \\
\hline \multirow[t]{6}{*}{ Luo et al. (2010) } & & Visual & & & \\
\hline & & Incongruous vs. congruous & $16-20$ & 0-200 ms, anterior & 16-20 Hz: lexico-semantic \\
\hline & & noun & & $400-657 \mathrm{~ms}$ & integration and reanalysis \\
\hline & & & $20-24$ & 0-200 ms, central & 20-24 Hz: reanalysis/repair process \\
\hline & & & & $400-657 \mathrm{~ms}$ & of prosodic structure \\
\hline & & $\begin{array}{l}\text { Defect vs. intact rhythmic } \\
\text { sentence pattern }\end{array}$ & $20-24$ & & \\
\hline van Elk et al. & & Visual & & & \\
\hline \multirow[t]{2}{*}{$(2010)$} & & Verbs in animal vs. human & 20-30 & $500-600 \mathrm{~ms}$ & Retrieval of action semantics, \\
\hline & & context & & Motor and premotor & Motor activation \\
\hline
\end{tabular}

left hemispheric decrease of overall MEG (magnetoencephalography) power specifically for the 5- to $15-$ and $15-$ to $25-\mathrm{Hz}$ range was shown (Singh et al., 2002). This decrease significantly correlated with the location of BOLD increases in an fMRI-experiment, which was interpreted in terms of increased neuronal activation during this task. Fisher et al. (2008) reported that beta activity in the MEG was a very robust marker for assessing language lateralization in healthy controls and a clinical patient during a verb generation task. The generation of verbs elicited decreases in beta power $(15-25 \mathrm{~Hz})$ in the left inferior frontal lobe. The beta decrease typically started at 250-500 ms after auditory noun presentation and sustained throughout the active phase of the task. However, the authors also reported on beta band increases $(12-20 \mathrm{~Hz})$ in the right frontal and superior-parietal lobes. Since this task relies on motor activation the beta decrease could be correlated with the typical motor-related beta desynchronization, whereas the beta increase could be related to neuronal synchronization over non-activated motor regions (Pfurtscheller and Lopes da Silva, 2011).

van Elk et al. (2010) have also found a beta $(20-30 \mathrm{~Hz})$ decrease in the premotor cortex whilst participants processed action verbs without having an explicit motor task. Verbs were embedded in visually presented sentences that either described a human action or an animal action. The decrease of beta power was stronger for verbs around 400-600 ms presented in an animal compared to a human context and was inversely related to a N400 size effect. Thus, a stronger motor activation was found for verbs in an animal context. This was interpreted in terms of motor activation in language processing to primarily support the retrieval and integration of lexical-semantic information rather than post-lexical motor imagery of specific movements. For instance, the verb "swimming" is semantically more closely associated with the noun " $d u c k$ " than with the word " $m a n$ " since animals have only limited action capabilities in comparison to men. Therefore, the ease of the retrieval of action semantics for a certain word is expressed by the degree of beta power decrease and indicates that processing of action verbs is accompanied by mental motor activation (van Elk et al., 2010).

Likewise, in a study on the perception of visually or auditorily presented action and non-action verbs (e.g., to run vs. to rest) a significant power difference in dependence of the topography of electrodes was found. At central electrodes, the action verbs showed significantly lower beta power $(13-25 \mathrm{~Hz})$ than non-action verbs, whereas at anterior regions, the effect was reversed. This was shown as well as for the visual as the auditory presentation and is another hint that beta oscillations reflect motor-related semantics of words. These findings were supported by an EEG coherence analysis showing significant coherence increases in the beta band $(19-25 \mathrm{~Hz})$ over central electrodes for action verbs (Weiss et al., 2001; Figure 1).

Figure 1 demonstrates coherence differences for action and non-action verbs compared with a baseline condition. It could be shown that there are more and stronger significant coherence changes over central electrodes for action compared to non-action verbs. This fits to findings showing that the EEG could separate even verbs referring to actions executed with the leg (e.g., to kick), arm (e.g., to pick), or face (e.g., to lick; Pulvermueller, 2005). It must be noted that in the study of Weiss et al. (2001) a beta power decrease was associated with a beta coherence increase. This seemingly contradictory finding can be resolved considering the different interpretation of power and coherence changes and their reflection of different neuronal scales (see Neuronal Scale).

A beta power decrease has also been observed in students of translation and interpreting who had to do a simple word translation task from English to German. During the translation of visually presented words, a higher beta power $(20-30 \mathrm{~Hz})$ decrease was observed $400 \mathrm{~ms}$ after the presentation of high-frequency words opposed to low-frequency words (Grabner et al., 2007). However, this beta band decrease may be more accurately related to earlier and stronger motor preparation for responding to high-frequency words rather than to language processes per se.

Klimesch et al. (2001) showed that beta power (about 14$16 \mathrm{~Hz}$ ) revealed the most selective results concerning differences between dyslexic participants and healthy controls in a reading task. Both groups showed a stronger beta power decrease over left frontal and parietal sites for the pronunciation of meaningful words in contrast to pseudowords. However, whilst dyslexic children read words, their beta band activity did not decrease as much as that of healthy controls. This finding was interpreted in 


\section{Verb processing (beta 19-25 Hz)}

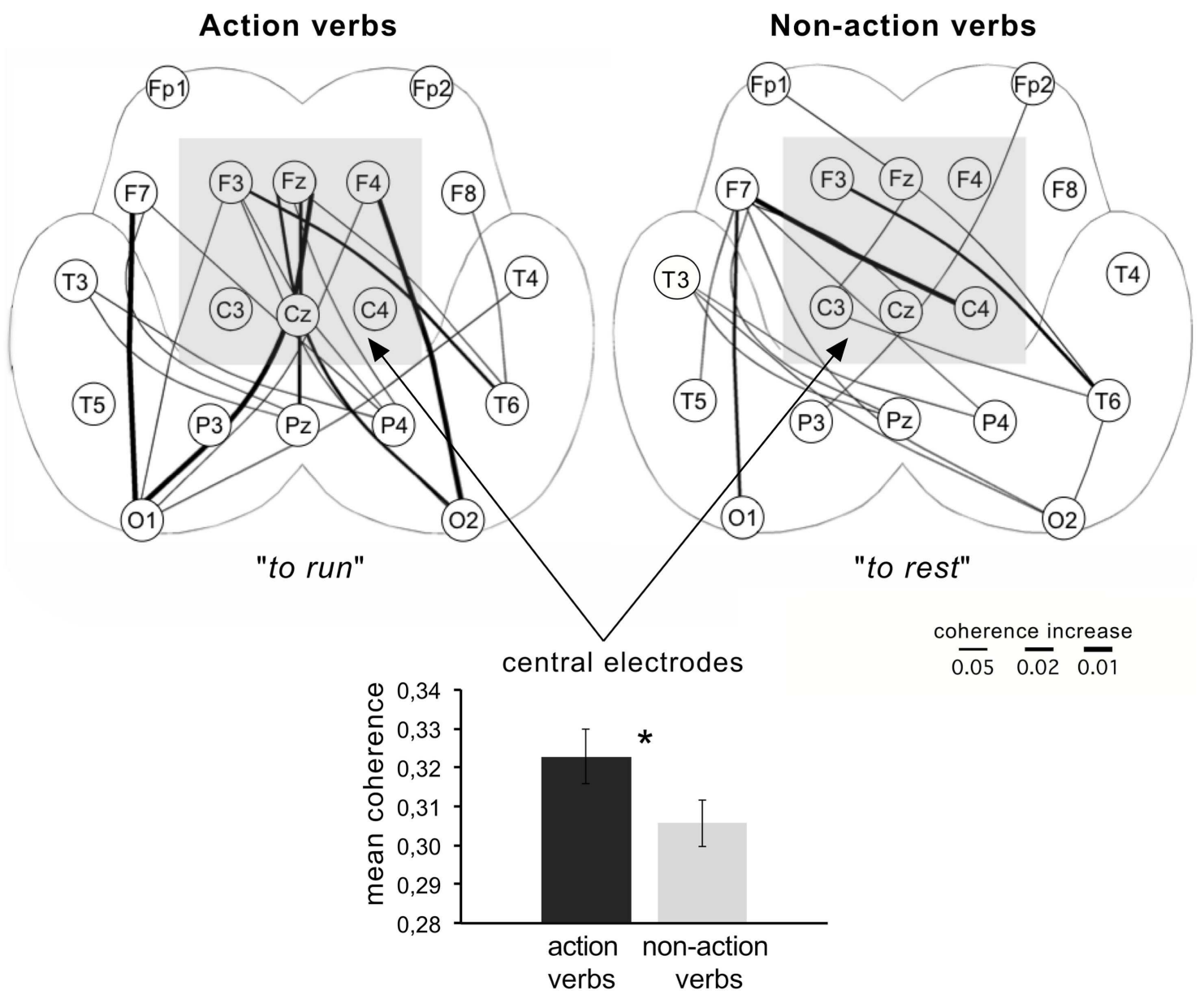

FIGURE 1 | Coherence differences for the processing of action and non-action verbs compared to a resting baseline condition. Lines between electrodes mapped on the unfolded schemes of both hemispheres denote significant coherence increases. For the evaluation of significant coherence differences paired Wilcoxon-tests were applied. The rank sums obtained were converted to error probabilities, which were presented in probability maps. Mean coherence at central electrodes (indicated by the shaded square) is significantly higher for action compared to non-action verbs (based on data from Weiss et al., 2001). terms of a disturbance of the grapheme-phoneme conversion in dyslexic patients reflected by the betal activity. For that reason, the missing beta desynchronization may be related to a possible deficit in flexible behavior and cognitive control during reading in these patients. A somewhat related result was described by Penolazzi et al. (2010) who found a large beta power $(13-20 \mathrm{~Hz})$ increase at posterior sites for dyslexic children after a 6-month phonological training in comparison to pre-training beta activity. The children who showed the greatest enhancement in reading speed showed the largest left posterior beta power increase. High left hemisphere beta band activity turned out to be the most reliable indicator of language lateralization and reorganization in children and adults.

To summarize, beta band desynchronization, which is associated with language processing, was commonly found as a result of motor activity, motor preparation, and mental motor simulation (e.g., during the processing of action verbs).

\section{MAINTENANCE OF THE ACTUAL STATE (EXPECTANCY VIOLATION)}

Hence, in contrast to the hypothesis established over the past years that beta oscillations merely indicate a cortical "idling rhythm" of the motor system, it turned out that beta oscillations reflect an active mechanism, which supports the activity of the motor system (Engel and Fries, 2010; Jenkinson and Brown, 2011). It could be shown that during increased beta synchronization voluntary movements were slowed down, whereas stretch reflexes that reinforce existing posture were improved (Gilbertson et al., 2005). Thus, it was hypothesized that synchronization of neuronal activity in the beta range is highly correlated with the maintenance of steady state force output and the temporary promotion of the existing motor activity (Engel and Fries, 2010).

This hypothesis was extended by Jenkinson and Brown (2011) who proposed that beta activity is inversely correlated to the likelihood that a new voluntary action will have to be processed 
or performed. Hence, beta desynchronization determines motor readiness and the degree of this suppression correlates with the predictive quality of cues signalizing the need for a certain action. Beta power decrease provides a running index of the extent to which internal and external cues predict the probability of new processing demands (Jenkinson and Brown, 2011). A related finding is the pre-stimulus suppression of beta band activity associated with the expectation of a tactile stimulus, which was interpreted in terms of a preparation of the relevant brain system for the processing of a (novel) forthcoming event (van Ede et al., 2010).

Thus, concerning language processing, one might suggest that if no change is expected in the language stimuli presented, beta activities will not change. However, beta will increase if the system has to maintain the actual language stimuli in memory, and it will decrease if the current cognitive state is interrupted by novel and/or unexpected stimuli. Consequently, a beta power decrease predicts the probability of new processing demands (Engel and Fries, 2010).

Kim and Chung (2008) found a significant decrease of beta band oscillations $(13-25 \mathrm{~Hz})$ in the MEG whilst patients with epilepsy performed an auditory oddball paradigm. In this experiment, Korean words were presented for about $400 \mathrm{~ms}$ auditorily to the patients. While the patients processed deviant stimuli, beta band activity decreased significantly at left frontal and temporal areas. The lateralization of this beta decrease matched the results of a previous Wada-test perfectly. These results underline the assumption that a beta power decrease reflects the occurrence of an unexpected, unfamiliar stimulus. Similarly, Shahin et al. (2009) found a sustained decrease of lower beta frequencies $(13-20 \mathrm{~Hz})$ and a power increase of higher beta $(25-30 \mathrm{~Hz})$ for a semantic task with a maximum peaking between 500 and $600 \mathrm{~ms}$. Participants had to perform template matching in auditory memory (oddball experiment) based on the lexico-semantic analyses of nouns denoting animate and inanimate objects. According to their interpretation the beta increase indicated the maintenance of verbal stimuli in auditory memory. In contrast, the beta decrease was interpreted as reflecting enhanced motor preparation in anticipation of the response to unexpected deviant stimuli.

Davidson and Indefrey (2007) investigated the processing of sentences that had been grammatically violated compared to grammatically intact sentences. Participants showed a beta band $(14-30 \mathrm{~Hz})$ power decrease at the word, which grammatically violated the sentences. This has been interpreted as possibly increasing the cortical area that is recruited for grammatical processing (Davidson and Indefrey, 2007). Alternatively, the decrease of beta power at the word category violation could be interpreted as an indication of the occurrence of a new, unexpected event. In good agreement with the latter interpretation, Bastiaansen et al. (2010) found a sustained increase of beta power $(13-18 \mathrm{~Hz})$ over frontal regions across correct sentences in contrast to sentences with a word category violation. In this MEG experiment, subjects read correct sentences, sentences with a word category violation, and sentences without a syntactic structure. Correct sentences were associated with a linear trend of increasing beta power. This beta power increase was disrupted in sentences with a word category violation and was absent in sentences without a syntactic structure. Therefore, the authors relate the neuronal synchronization in the lower beta band to syntactic unification operations. However, the beta increase could also be correlated with the maintenance of the current state during processing of correct sentences, which is interrupted by unexpected, syntactically incorrect stimuli.

A beta power decrease was also described for unexpected semantic violations. In an experiment with semantically incongruous and congruous Chinese sentences beta power $(16-20 \mathrm{~Hz})$ was significantly reduced for the critical nouns in the visually presented incongruous sentences at anterior regions (Luo et al., 2010). This decrease has been found as well for an early time window $(0-200 \mathrm{~ms})$ as for a later time window (400-657 ms) after word onset. In the same way, in an experiment on the semantic plausibility judgment of auditorily presented congruent and incongruent German sentences the betal band power $(13-18 \mathrm{~Hz})$ significantly decreased at the incongruent word compared to a baseline before sentence onset. These significant decreases were predominantly found at frontal, central, and left hemispheric electrodes. Congruent nouns did not show this decrease, but actually showed a power increase at right posterior electrodes (Figure 2).

Whilst participants processed these congruous and incongruous sentences, the critical noun was also associated with significant changes in the beta band coherence $(25-30 \mathrm{~Hz}$; Weiss and Jannek, 2007; Weiss et al., submitted). Whereas congruous words elicited beta coherence increases predominantly at left hemispheric lateral temporal and frontal electrodes, incongruent words showed a significant network of beta coherence increases at posterior temporal electrodes and massive decreases at frontal and right hemispheric electrodes. In contrast to the power desynchronization, these coherence changes might reflect an additional pattern of neuronal activation during sentence processing. Left hemispheric frontal and temporal power decreases might hint at an increase in local information processing due to the need of updating the system since participants were confronted with unexpected stimuli. The left hemispheric coherence increase, on the other hand, might reflect the more intense binding of neuronal activity across a long-range connection showing activation processes at other scales. In contrast, the power increase combined with the coherence decrease at right frontal sites may be interpreted differently, although their function is not clear at present. This is another indication for the importance to monitor power as well as coherence measures in order to obtain a more complete picture of the neuronal dynamics going on during language processing (see Neuronal Scale).

The violation of expectancy is also related to top-down attention, which is frequently associated with a beta power decrease during language processing (e.g., Bastiaansen et al., 2005; Kim and Chung, 2008). Bastiaansen et al. (2005) investigated EEG power differences between visually presented open class (nouns, adjectives, verbs) and closed class words (articles, prepositions, and conjunctions). These words were part of a text that participants had to comprehend while their EEG was recorded. Beyond findings in the theta and alpha range a significantly stronger beta power decrease $(16-21 \mathrm{~Hz})$ was found $200-500 \mathrm{~ms}$ after the presentation of the open class words at occipito-temporal electrodes. Most likely, open class words are attended more thoroughly due to their high importance for language comprehension. In correspondence with this finding, an MEG-study on the emotional 


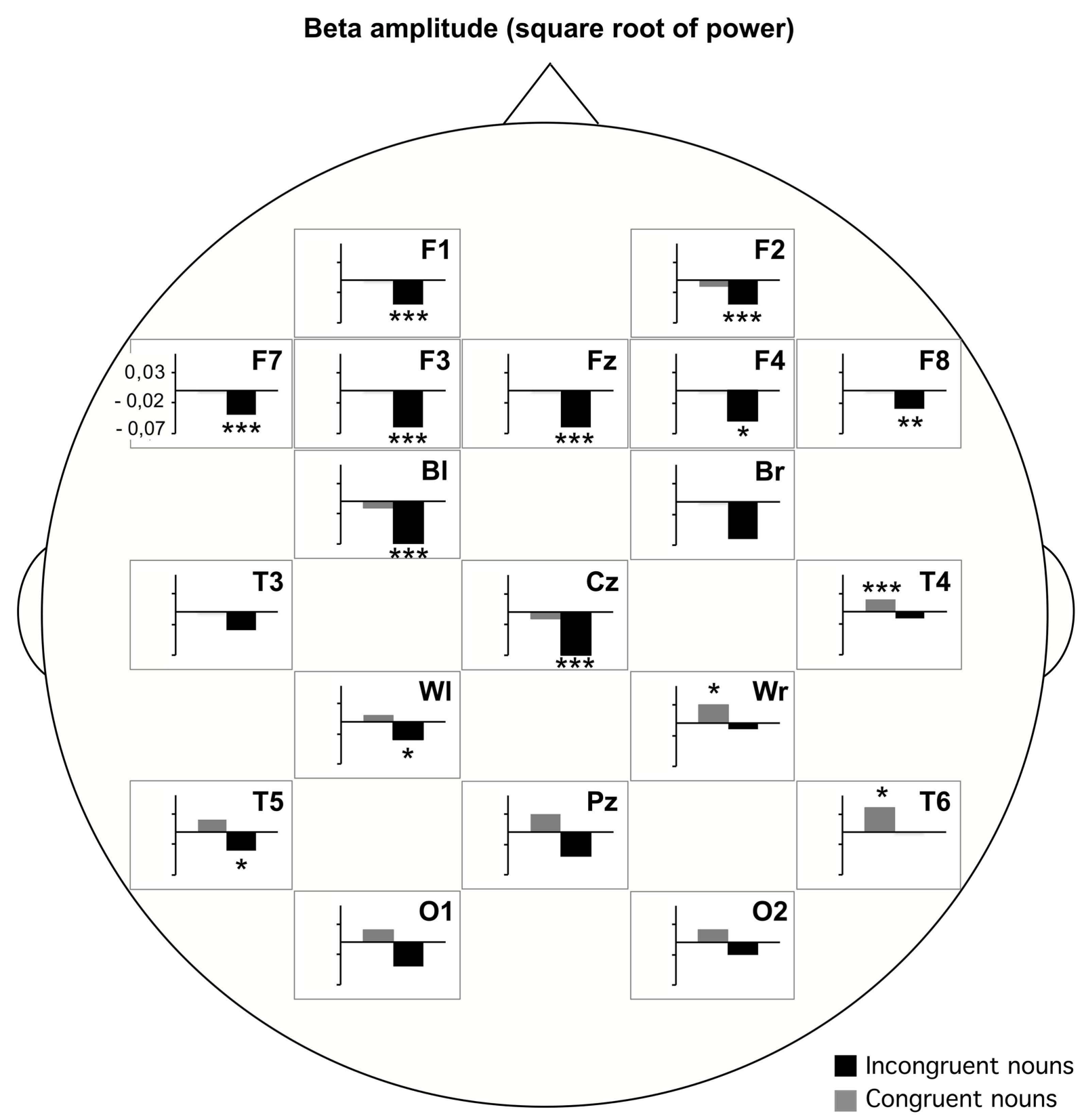

FIGURE 2 | Beta1 (13-18 Hz) amplitude (square root of power) differences for incongruent and congruent nouns compared to a pre-sentence baseline. Post hoc paired $t$-tests at each electrode revealed significant differences based on the data of 29 participants (Weiss et al., submitted). connotation of written words revealed a higher power decrease in the beta band $(13-30 \mathrm{~Hz})$ in the anterior cingulate cortex and the left inferior or middle frontal gyrus for emotional words. This was not the case for non-emotional words (Hirata et al., 2007). Left dominant beta decrease in prefrontal regions was higher for emotionally negative words (e.g., sadness), whereas right dominant beta decrease has been found for emotionally positive words (e.g., happiness). Thus, the higher-order emotional evaluation of the words modulates beta band changes in prefrontal areas according to their role in cognition and attention (Hirata et al., 2007).

\section{BINDING FUNCTION OF BETA}

The maintenance of the actual state of stimuli and the processing of unexpected language stimuli is certainly related to another important requirement language processes set to the cognitive system, namely the binding of temporally segregated information. In order for speech comprehension to function adequately, for example, certain components of a particular speech stimulus occurring simultaneously, like its physical, phonological, morphosyntactic, semantic, pragmatic, and suprasegmental aspects must be bound into a single coherent unit. Only then can the meaning of a particular utterance be understood and, if necessary, initiate an 
appropriate response. The elements of a spoken sentence such as "Paul tells Tom that Julia is angry because she didn't pass the exam" only gain meaning in the hearer's mind if, along with the physical characteristics of the speech signal, the individual perceived sounds are bound to meaning-carrying words in the brain. It must not be forgotten that the hearer must maintain a representation of previously bound information about formerly uttered words in working memory while perceiving the new auditory input. It is self-evident that such hierarchical binding processes must take place during speech production, i.e., the planning and production of main and subordinate clauses as well as during speech reception.

Over the past years, a set of studies has pointed to the functional role of beta frequencies serving such language-related binding at the word and sentence level. Frequency band specific results in the betal band were found in a study of von Stein et al. (1999), which assumed that this frequency band reflects semantic binding during word processing at left temporo-parietal areas. Correspondingly, the processing of different auditorily or visually presented word categories (nouns, proper names, verbs, pseudo words) was associated with network of coherence changes that differed between categories particularly in higher frequencies (11$31 \mathrm{~Hz}$ ) suggesting that activity within higher frequencies reflects the syntactic and semantic differences between particular word categories (Weiss and Rappelsberger, 1998; Weiss and Mueller, 2003). For example, the most consistent differences between the processing of auditorily presented concrete and abstract nouns were found in the betal band $(13-18 \mathrm{~Hz}$; Weiss and Rappelsberger, 1996). The importance of the betal band for semantic categorization and binding could be impressively underlined by the application of machine learning techniques to the EEG data either containing concrete or abstract words (Lingner, 2005). The analysis with "ordered means models (OMMs)" showed that in the EEG signals the betal band is able to reveal an on-line classification of concrete vs. abstract nouns with a probability of about $80 \%$.

Binding processes are even more important during sentence processing. During the performance of a gap-filling task increases in beta coherence (roughly around $16 \mathrm{~Hz}$ ) between frontal and parietal leads have been correlated with the activation of semantic working memory (Haarmann et al., 2002). However, the higher coherence during the performance of the gap-filling task can also be correlated with the need for syntactic binding (Bastiaansen et al., 2010). These syntactic operations are certainly more difficult for the gap-filling task and thereby in turn require more activity of the semantic working memory system. It is well-known that the ventral prefrontal cortex is involved in the maintenance of stimuli in working memory in the absence of sensory input (Levy and Goldman-Rakic, 2000), which likely relates this region to syntactic binding. Thus, both semantic working memory operations and syntactic binding may contribute to changes in the beta band at left prefrontal regions.

This assumption is underlined by a study on power and coherence changes associated with the processing of English subjectsubject- (SS) and the more demanding subject-object-relative clauses (SO; Weiss et al., 2005). Participants had to comprehend auditorily presented sentences such as e.g.,
SS-sentence: The fireman who attacked the senator sued the city over working conditions.

SO-sentence: The fireman who the senator attacked sued the city over working conditions.

Prominent decreases of betal power $(13-18 \mathrm{~Hz})$ could be found for the more demanding SO- compared to SS-sentences in the relative clause and the interval after the relative clause. The differences between the sentence types were significant for the relative clause interval mostly at left and right frontal electrodes but also at posterior electrodes. Yet again, left hemispheric decreases of beta power in the relative clause interval might indicate the occurrence of an unexpected sentence phrase and the need for syntactic binding. In contrast, no beta coherence differences were found in the relative clause interval. Significant coherence difference between SO- and SS-sentences was found in the betal band (13$18 \mathrm{~Hz}$ ) in the post-relative clause interval only. In this sentence interval, semantic-pragmatic analysis in the sense of building up action-related scenarios has to be performed. In the post-relative clause region the thematic roles of the SO-sentence must finally be resolved. Thus, an association of betal activities with the semanticpragmatic analysis during this sentence interval is reasonable. Beta oscillations are presumably involved in the building of scenarios and possibly in the binding of semantic word-knowledge from semantic memory in support of meaning construction (Weiss et al., 2005).

High beta band activity has also been postulated to be associated with strong endogenous top-down components of a task (Engel and Fries, 2010). A task, which needs highly endogenous binding functions, is the processing of figurative language. In an EEG-study of Berghoff et al. (2005) 29 participants had to comprehend literal and figurative German sentences such as:

literal: "Sie hilft dem Schauspieler auf die Buehne."

(She helps the actor onto the stage.)

figurative: "Sie hilft dem Schauspieler auf die Spruenge."

(She gives the actor a helping hand.)

EEG coherence was calculated for three sentence intervals, (1) the interval before the figurative meaning can be encountered, (2) the interval while the figurative meaning is encountered, and (3) the interval after the sentence. Although other frequency bands have been studied, only the betal band $(13-18 \mathrm{~Hz}$ ) could reliably reflect whether participants had heard a figurative or a literal sentence. Figurative compared to literal sentences elicited coherence increases within the left and the right hemisphere. However, the strongest differences were found for coherences between the hemispheres (Figure 3).

Interestingly, higher coherence was found between the hemispheres for figurative compared to literal sentences. Furthermore, this strong difference only appeared during the moment at which the figurative meaning was retrieved (interval 2; Berghoff et al., 2005). These results showed that neuronal processes in betal only differ from the very moment the figurative meaning is retrieved, and that neither the left nor the right hemisphere alone but the cooperation between both hemispheres plays the most important role. In that way, the beta band is an indicator of endogenous linguistic binding during the processing of figurative vs. literal language pointing at the special role of figurative language. 


\section{Figurative versus literal sentences}

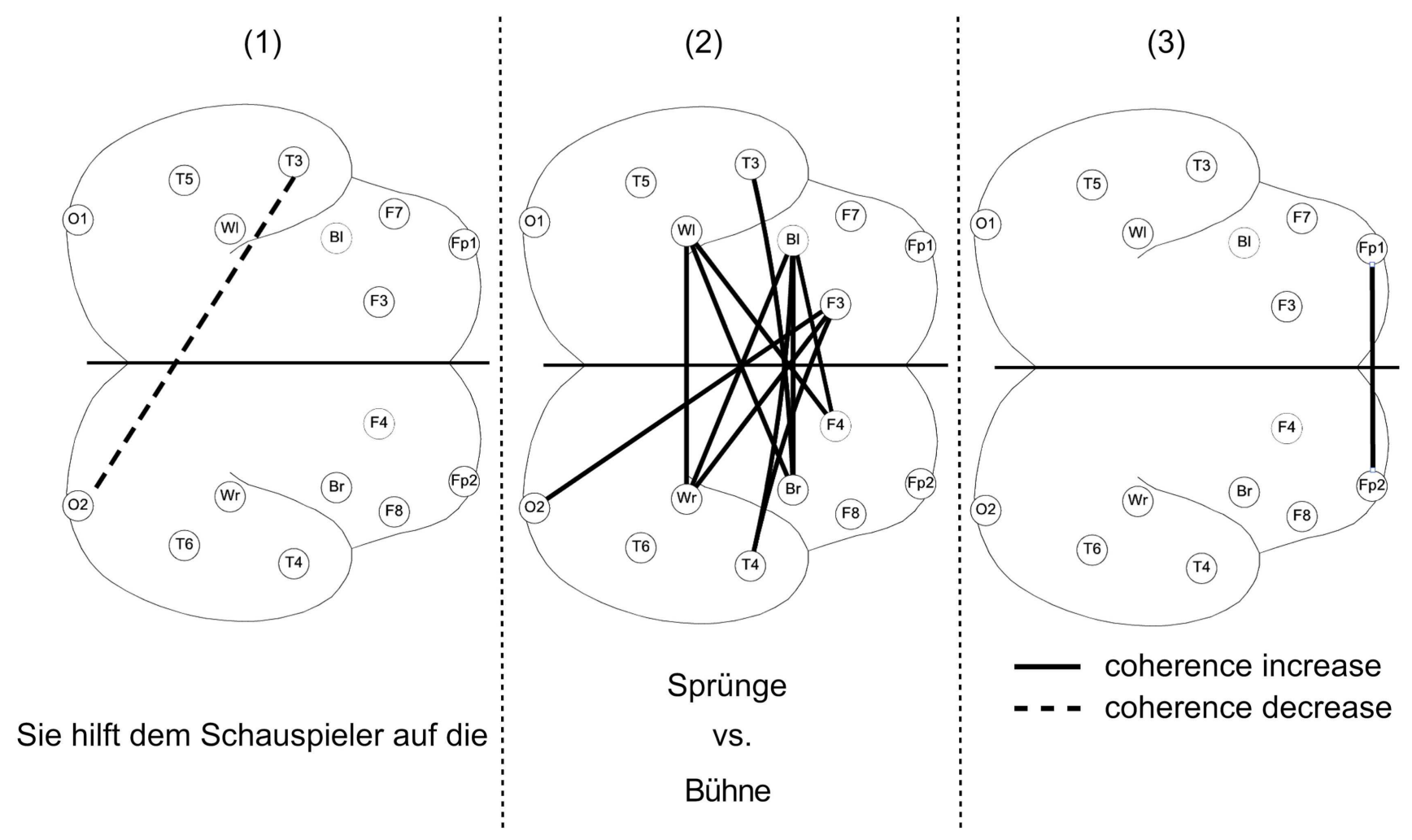

(She gives the actor a helping hand versus

FIGURE 3 | Significant coherence differences between figurative and literal sentences for the interval before the figurative meaning can be encountered (1), the interval while the figurative meaning was she helps the actor onto the stage)

encountered (2) and the interval after the sentence (3). Coherence differences were mapped as lines (Berghoff et al., 2005, modified). Further information, see Figure 1.

\section{MEMORY RELATED BETA}

So far, changes in beta band activation seem to be related not only to the involvement of top-down processing but also to the contents of the signal. Beta activity increases when the maintenance of the actual state of the stimuli is more important for the task than the attention to new stimuli. Correspondingly, an increase of frontal beta band activity $(15-20 \mathrm{~Hz})$ was observed whilst participants had to perform a delayed matching-to-sample task (Tallon-Baudry et al., 1999). For that reason, an increase of beta is also associated with the functional role of holding an object representation active in visual short-term memory. These results support the hypothesis that oscillatory beta synchronization serves to bind distributed sets of neurons into a coherent representation of memorized contents. Similarly, during memorization of syllables a linear increase in beta activity as a function of memory load was found. This increase was interpreted as the representation of task-relevant stimulus features during memorization in the absence of sensory input (Leiberg et al., 2006).

However, Hanslmayr et al. (2012) have provided evidence that beta power desynchronization and not synchronization, is strongly related to memory encoding and retrieval. They believe that the richness and the amount of information encoded correlates with beta desynchronization. For instance, Hanslmayr et al. (2009) showed that in an incidental memory paradigm the deep semantic encoding of later remembered words has been associated specifically with beta power decreases $(12-20 \mathrm{~Hz}$ ) at left frontal and parietal electrodes, whereas a shallow encoding task did not elicit such an effect. The beta power decrease for later remembered items in the deep semantic encoding task was significant between 500 and $1500 \mathrm{~ms}$ after word onset and turned out to be related to the processing of the items' semantic features (Hanslmayr et al., 2009).

A partially related experiment was reported by Weiss and Rappelsberger (2000), who studied the EEG power and coherence associated with semantic memory encoding of German nouns. In contrast to the study above an intentional learning paradigm was used. Nevertheless, results revealed a beta power $(13-18 \mathrm{~Hz})$ decrease during the memory encoding of visually presented nouns compared to a baseline condition. In accordance with the findings described above, the memory encoding of later recalled nouns elicited a more pronounced beta power decrease (see Figure 4A, 


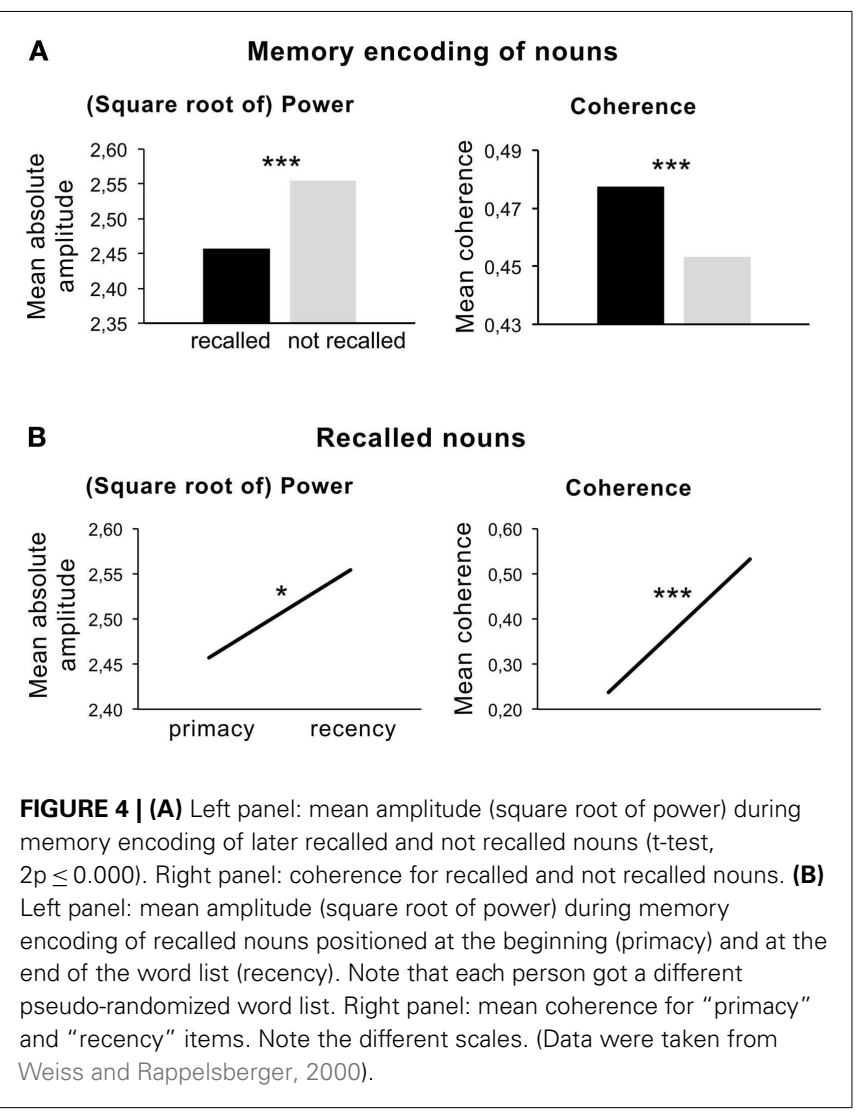

left panel). This betal decrease is related to the more intense encoding of the semantic features from the later recalled nouns as postulated by Hanslmayr et al. (2009) and possibly related to increased attention to these words.

However, these findings contradict the assumption that an increase of beta power is related to the maintenance of memory items in mind. Interestingly, the comparison of betal power for recalled items, which were positioned either at the beginning or at the end of the word list presented (serial position effect), revealed a significantly higher beta power for the recalled words at the end of the word list. This result, however, underlines the relation of a beta power increase associated with working memory processing. Items positioned at the beginning of the word list are more effectively stored in long-term memory due to rehearsal effects, whereas the last items are still present in working memory. Figure 4B (left panel) shows a significant power increase in beta for the recalled nouns positioned at the end of the list.

This means that the on-line deep semantic encoding of the recalled compared with the not-recalled nouns is associated with a beta power decrease. Simultaneously, beta power increases while later recalled nouns are encoded and is highest at the end of the list, where stimuli still were in working memory. The later finding correlates to the active maintenance of the stimuli in memory. Accordingly, the role of beta in this experiment remains twofold. Possibly, two different betas, which overlap and reflect different mechanisms during the encoding process, are involved in this task. This assumption may be underlined by the results of the coherence analysis (Figures 4A,B, right panel). Figure 4 shows that coherence was higher during the semantic encoding of the later recalled items and increased from the first to the last items. These results also point to the involvement of different scales of local and long-range synchronization, possibly covering different neuronal mechanisms during word encoding.

\section{DIFFERENT WINDOWS ON BETA OSCILLATIONS}

Before summing up the role beta oscillations might play during language processing in Section "Beta Oscillations and Language: A Synopsis," it is important to consider the mixing-up of different analysis methods and parameters, which adulterates and complicates the interpretation of the results. According to findings from literature and own results, it seems that at least three main factors have to be taken into account when interpreting findings in the beta frequency range (and certainly other frequencies) related to language processing (Figure 5):

1) the frequency range in the beta band [e.g., low $(13-20 \mathrm{~Hz})$ vs. high $(20-30 \mathrm{~Hz})$ ] and the time interval [early (0-200 ms) vs. late $(400-600 \mathrm{~ms})]$.

2) the neuronal scale (e.g., power or coherence).

3 ) the direction of change (increase vs. decrease) and the topography (e.g., motor system or association cortex).

\section{FREQUENCY RANGE AND TIME INTERVAL}

Many different aspects of language tasks are associated with distinct findings in the beta frequency range, although they often are related. Based on these findings, it has to be hypothesized that beta oscillations are not a unitary phenomenon but consist of divergent rhythms with different physiological properties and, hence, different cognitive relevance. As has been frequently proposed in the quoted literature (Pfurtscheller et al., 1997; Kopell et al., 2011) and as has been observed in own experimental results, there seems to exist not only a single beta frequency band but different betas, which possibly can be associated with different aspects of language processing. Often low (13-20) and high (20-30) frequencies in beta reveal contrasting results such as, for example a power decrease in the $13-$ to $20-\mathrm{Hz}$ band and a simultaneous increase at $25-30 \mathrm{~Hz}$ possibly reflecting different cognitive aspects of a language task (Shahin et al., 2009). Similarly, a power decrease at $16-20 \mathrm{~Hz}$ in an early time window after stimulus onset can be related to semantic aspects, whereas a decrease in $20-24 \mathrm{~Hz}$ in a later time window can be ascribed to prosodic aspects of a task (Luo et al., 2010).

Further, there is neurophysiological evidence which underlines the existence of different betas. First, there might be different neuronal generators underlying these beta frequencies (Roopun et al., 2006), which contribute for example to either syntacticor motor-related effects. For instance, the beta2 rhythm (20$30 \mathrm{~Hz}$ ) is generated by pyramidal cells of deep cortical layer $\mathrm{V}$, a layer where some of the output information is going to the thalamus during motor processes (Roopun et al., 2006). Second, some beta oscillations are relying on inhibition, whereas others are associated with excitation. Third, beta oscillations often occur during sleep and deep anesthesia and hence are generated also in states of unconscious behavior (e.g., Amzica and Lopes da Silva, 2011). Fourth, it has been shown that synchronization in the beta 


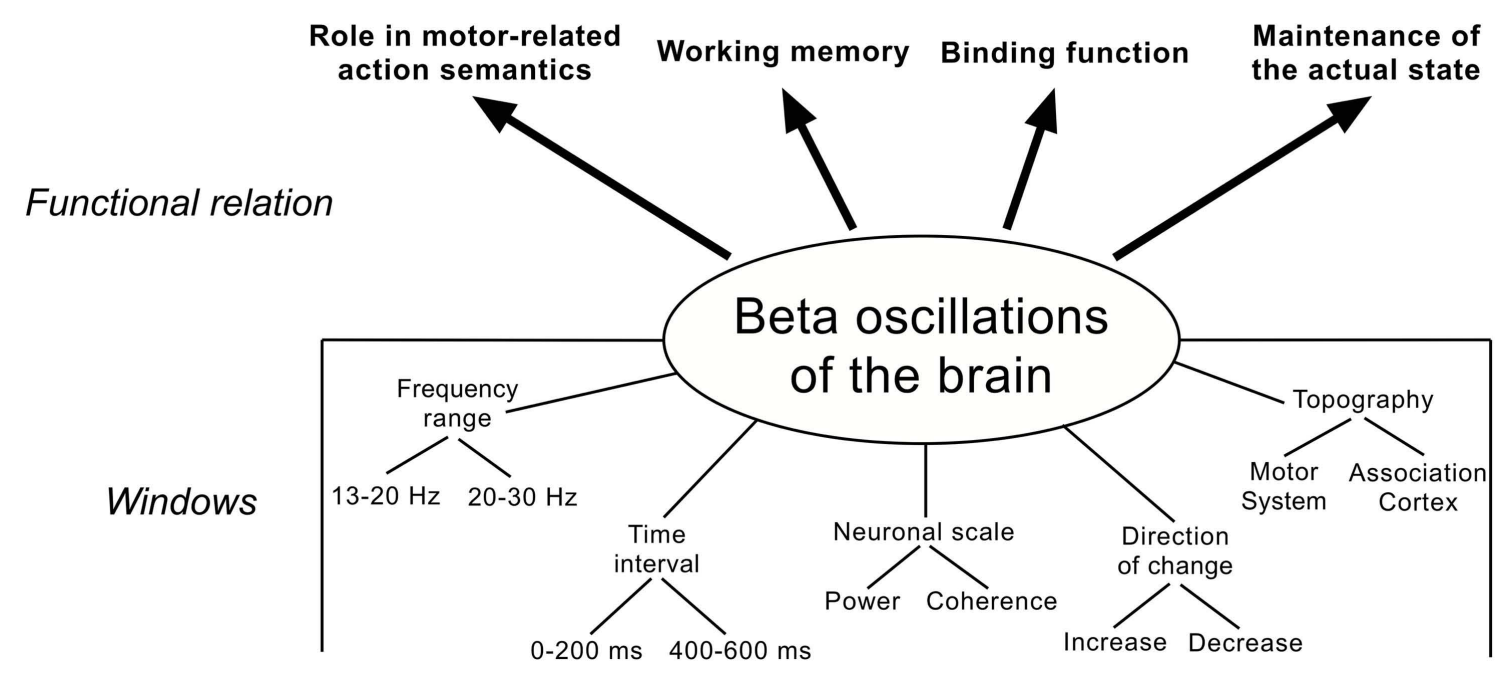

FIGURE 5 | Functional involvement of beta oscillations in language processing (upper part) and windows for measurement and interpretation (lower part).

range across long distances (long conduction delays) seems to be based both on interneuron activity and plasticity as well as on an interaction between pyramidal neurons and interneurons (Bibbig et al., 2002). Thus, it was proposed that interneurons and pyramidal neurons play a different role in the generation of lowand high-frequency synchronization (Kopell et al., 2000; Roopun et al., 2006; Scheeringa et al., 2011). These physiologically distinct beta oscillations differ in topographical extent and in frequency composition. They might be associated with different cognitive functions and thereby might play different functional roles in cognitive and language processing. It seems as if there exist motor and sensory-related as well as more cognitive-related and associative beta oscillations both contributing to different aspects of language processing. However, the neurophysiological and cognitive relevance of "different betas" are still debated.

In addition to findings in a single frequency range, it has to be considered that cross-frequency interaction might play an important role during cognitive processing (e.g., von Stein et al., 2000; Schack and Weiss, 2005; Jensen and Colgin, 2007). It could be that there is not only a linear or non-linear interaction between beta and theta or gamma frequencies but also a physiological grounded interaction between different frequencies within the beta range. For instance, a nesting of gamma and beta 2 frequencies in the betal frequency band was demonstrated under certain conditions (Kopell et al., 2011). Accordingly, lower frequencies may often support and modulate the activity in higher ones.

\section{NEURONAL SCALE}

Another fact which possibly confounds the interpretation of findings concerns the analysis method applied and the parameters investigated. In order to capture time- but not phase-locked (induced) events, advanced spectral analytical techniques (e.g., Fourier transform, wavelet transform, bandpass filtering) are used in order to assess statistical properties of oscillations in different frequency bands. One of the most frequently studied spectral parameter is the amplitude or power (squared amplitude) spectrum, which provides information on the frequency content of the particular analysis epoch of the EEG signal of a single electrode. The power spectrum at one electrode integrates cortical input under a scalp surface of the order of approximately $10 \mathrm{~cm}^{2}$ (Nunez, 2000) and reflects to which extent the neurons generating the EEG are oscillating synchronously at various frequencies. Power measures are suited to detect rather "local" changes in synchronization in contrast to cross-spectral functions such as coherence or phase coherence. The latter measures allow the investigation of neuronal "large-scale" interaction, which is also of particular interest for the study of cognitive processes.

EEG coherence is obtained by cross-spectral analysis and allows to quantifying the relationships between different signals. Coherence is a linear correlation coefficient and may be interpreted as a measure for the stability of phase between the same frequency components of two simultaneously recorded EEG signals. In the last years, several studies have suggested calculating phase coherence (phase synchronization) in place of coherence calculations (e.g., Lachaux et al., 1999). The reason for this is that coherence is indeed one possible measurement of phase synchronization, but it is dependent upon the signals' amplitude as well as relative phases between two EEG channels, and, therefore, not ideal in some cases. One advantage that arises from coherence measurements, in comparison to measuring phase synchronization directly, is that they are weighted to the benefit of signal epochs with large amplitudes (Nunez and Srinivasan, 2006). Large amplitudes in the EEG signal reflect a good signal-to-noise ratio allowing for more stable phase approximations. The exclusive use of phase information (independent of amplitude) gives the same weight to signal segments, regardless of whether they have high or low amplitude. Therefore, the estimation of phase coherence is much more vulnerable to background noise that has no functional relevance. For this reason, it is important to, at the very least, present a large quantity of trials when analyzing phase synchronization - certainly, a task that is not always easy for language research. Consequently, the analysis of coherence is, under certain circumstances and in certain paradigms, a compromise, which is more adequately suited for the investigation of language processing. Accordingly, it was 
this method that was predominantly used in our own studies cited in Section "Experimental Evidence on Beta Oscillations and Language."

Another problem which arises with coherence analysis is the spatial filtering by volume conduction into the two signal electrodes (Nunez and Srinivasan, 2006). Therefore, the significance of changes in coherence must be analyzed and interpreted with caution especially when the power at two electrodes and the coherence between them show the same directional changes (in- or decreases). In the coherence studies cited in Section "Experimental Evidence on Beta Oscillations and Language," interpretations of results were mainly based on findings concerning far removed (large-scale; $>10 \mathrm{~cm}$ ) electrodes. Additionally, the direction of power changes for neighboring electrodes was analyzed in addition to coherence.

At any rate, it has to be emphasized that the relationship between scalp EEG power and long-range coherence and their possible interpretation with respect to the underlying neurophysiological activity is uncertain and still a matter of great debate because of the complicated three-dimensional structure of the brain (Nunez and Srinivasan, 2006). Whereas power changes reflect local processing, coherence, and phase coherence are suited to monitor neuronal long-range interaction. Accordingly, these measures have to be considered separately and interpreted differently. Various examples of cognitive information processing point at the fact that there is no simple relationship between power and coherence measures (e.g., Siegel et al., 2012). For example, during memory encoding of nouns (Weiss and Rappelsberger, 2000) as well as during processing of relative clauses (Weiss et al., 2005) a simultaneous power decrease and coherence increase in beta has been found. Furthermore, both an EEG power decrease and a coherence increase occurred together with an increase of the BOLD signal during fMRI (Knyazeva et al., 2006).

\section{DIRECTION AND TOPOGRAPHY}

Besides, the direction of parameter change seems an important factor, which has to be considered when interpreting frequency band-related results. A beta power decrease in the motor cortex (Pfurtscheller and Lopes da Silva, 2011) as well as a beta power increase in left frontal regions during sentence processing (Bastiaansen et al., 2010) might both be related to increased local neuronal activation. It is clear that the topography of changes observed is relevant here. Whereas motor-related beta changes mostly have been found at central sites, language-related changes were predominantly found at left frontal and parietal sites. Moreover, it seems important to consider the modality of stimulus presentation in this context. Most of the studies that reported on power decreases during various language tasks investigated the processing of visually presented stimuli. If the studies used auditory stimuli, they often found power increases beside the common decreases. Therefore, further studies have to investigate whether there indeed exists an influence of stimulus modality on the direction of parameter changes (Weiss and Rappelsberger, 1998; Krause et al., 2006).

In summary, the different analysis windows discussed in this section have to be taken into account when interpreting the role of beta oscillations in language processing. They may help to resolve several inconsistencies in the experimental results. Apart from that, the investigation of beta oscillations seems particularly promising with regard to language processes since the neurophysiological and psychophysiological background of such oscillations makes them especially suited for the various demands of language processing. The following section summarizes the possible relation of beta oscillations to four distinct, though overlapping, sub-processes of language.

\section{BETA OSCILLATIONS AND LANGUAGE: A SYNOPSIS}

Current experimental and neurophysiological evidence suggests a functional relationship between four different sub-processes of language and oscillations in the beta frequency range:

1) Beta oscillations correlate with motor processes in action semantics. The most well-known attribute of beta oscillations is their relation to motor processes. In action-oriented studies a decrease in beta power consistently reflects activation of the motor system for the performance of either action execution or observation (e.g., Babiloni et al., 2002; Hari et al., 1998). In accordance with these findings, language production is strongly associated with a beta decrease (e.g., Fisher et al., 2008; Singh et al., 2002). Interestingly, beta changes at premotor and motor regions have also been found during language tasks without the involvement of a motoric component [see Action Semantics (Motor-Related Beta)]. For instance, van Elk et al. (2010) found a beta decrease at premotor regions during the processing of action verbs, which was interpreted as reflecting the retrieval and integration of action semantic information. Similarly, during verb perception both a beta power decrease and coherence increase have been found at central electrodes for action vs. non-action verbs (Weiss et al., 2001).

Concerning the role beta plays in motor processing but also in motor imagery and action recognition it may be speculated that beta activities reflect the close relationship between language comprehension and motor functions - one of the core claims of current theories on embodied cognition. Embodied language theories state that language is processed in terms of mental simulations, which is commonly defined as the mental reenactment of perceptual, motoric, introspective, and affective states during cognitive function (e.g., Barsalou, 2008). If there is a special role of the sensorimotor system for language processing, then beta is a good candidate to indicate mental activation of motor-related systems during language processing. Results on beta oscillations accompanying semantic word processing (e.g., Weiss and Mueller, 2003) and the processing of action verbs (Weiss et al., 2001; van Elk et al., 2010) might support this assumption.

2) Beta oscillations are related to attention and expectancy violation. It has been proposed that a beta band enhancement is associated with the maintenance of the actual state of motor and cognitive processes whereas a beta band decrease is associated with the interruption of the cognitive state by novel and unexpected stimuli (Engel and Fries, 2010; Jenkinson and Brown, 2011). This correlates with findings showing that, in general, the prediction of upcoming stimuli most likely involve 
beta activity (e.g., Fujioka et al., 2009; Arnal et al., 2011). Studies done on word processing using oddball paradigms as well as on the processing of sentences that were semantically or grammatically violated underline this assumption. Whenever a novel and/or unexpected stimulus occurs or the current cognitive state is exogenously or endogenously changed, a beta decrease can be observed. For example, the processing of violated sentences coincides with massive frontal and parietal beta power decreases at the relevant words (e.g., Davidson and Indefrey, 2007; Bastiaansen et al., 2010; Luo et al., 2010). In contrast, Shahin et al. (2009) found a beta increase during the maintenance of verbal stimuli in memory and Bastiaansen et al. (2010) found an increase during the maintenance of the current state during sentence processing.

3) Beta oscillations are involved in binding mechanisms during language processing. For example, betal synchronization has been correlated with the binding of semantic features of different lexical categories (von Stein et al., 1999; Weiss and Mueller, 2003). A beta enhancement also has been found during syntactic unification in determining sentence meaning (Bastiaansen et al., 2010) and semantic-pragmatic analysis (Weiss et al., 2005). Betal synchronization even differentiated figurative vs. literal sentence meaning (Berghoff et al., 2005). These results support the hypothesis that oscillatory beta synchronization serves to bind distributed sets of neurons into a coherent representation of (memorized) contents during language processing. Furthermore, it has been suggested that large-scale cooperation in lower frequency bands is associated with endogenous top-down integration, whereas bottom-up signal processing occurs at higher frequencies (von Stein et al., 2000; Bastiaansen et al., 2005; Engel and Fries, 2010). In this context, Engel and Fries (2010) proposed that tasks involving largely endogenous top-down processes should come along with beta increases. This assumption was underlined by studies investigating the perception of ambiguous audiovisual stimuli or the comprehension of figurative language, which both are tasks involving strong endogenous components. Both tasks were associated with the occurrence of massive beta coherence increases (Berghoff et al., 2005; Hipp et al., 2011).

Using simulations with conductance-based models, Kopell et al. $(2000,2010,2011)$ showed that beta frequencies seem especially important and suited for preserving neuronal activity over time and consequently facilitating such binding functions. It was proposed that beta frequencies are used for higherlevel interaction between multimodal areas involving more distant structures and the binding of temporally segregated events, which is especially important for language processing (Kopell et al., 2000; Weiss and Mueller, 2003; Donner and Siegel, 2011). In particular, the betal oscillations $(13-18 \mathrm{~Hz})$ are unique in providing a mechanism for ongoing manipulation of cell assemblies (Kopell et al., 2010). Thus, betal is particularly suitable for higher-order processing in which it is necessary to compare old and new information as is common in language comprehension and, hence, linking past and present input. Because of that, Kopell et al. (2011) suggest that betal in particular responds differently to familiar and novel stimuli and is predestined in its behavior to maintain activity in the absence of continuing input. This relates to the finding that beta activity is enhanced during the maintenance of object representation in visual short-term memory (Tallon-Baudry et al., 1999).

4) Beta oscillations are related to memory processes. Particularly, Weiss and Rappelsberger (2000) demonstrated that beta power increased in the course of word encoding, and that sentence processing corresponded to the increase of memory demands (Bastiaansen et al., 2010). Correspondingly, beta coherence increased when complex SO-sentences were processed (Weiss et al., 2005) and during a gap-filling task when the load of semantic working memory was high (Haarmann et al., 2002). Experiments on visual object memory (Tallon-Baudry et al., 1999) and computer simulations underline the involvement of beta frequencies in memory processes. In particular, computer simulations predict that the ability of the betal rhythm to facilitate inter- and intralaminar interactions may form a substrate for short-term memory, which is independent of synaptic plasticity (Kopell et al., 2011). In addition, Hanslmayr et al. (2012) provided strong evidence that a very robust beta power desynchronization can be found during memory encoding and retrieval. This points at two different mechanisms present during memory processing: first, a local and short-lasting beta desynchronization which is directly related to the encoding of items, and, second, a more global, long-lasting synchronization related to the working memory load. Whether this assumption is true has to be proven in further experiments.

To summarize, beta frequency modulations are involved in various aspects of language processing. On the one hand, beta oscillations reflect semantic and sensory-motor features of word categories and lexical-semantic retrieval processes. On the other hand, beta has also been correlated with more complex linguistic sub-processes such as parsing as well as syntactic, and semantic binding operations. The beta's close relation to expectancy violation and attention points to its necessary involvement in topdown mechanisms during language processing. Furthermore, it can be postulated that the beta band plays a large role in memory processes. At present, it is not clear whether there are "different betas" that serve motor and sensory-related functions on the one hand, and, on the other hand, more cognitive-related and associative functions in language. However, the neurophysiological evidence points in this direction. Even though the current knowledge on the beta's role in language processing is quiet complex and findings are still contradictory, the investigation of beta oscillations in addition to ERP-analyses seems very promising. Animal experiments concerning the synchronization of oscillatory processes, together with computer simulations of neural networks as well as results of EEG spectral analysis techniques will have a large potential to enhance our knowledge on language processes in the future.

\section{ACKNOWLEDGMENTS}

This work was supported by the German Research Foundation (DFG; Cluster of Excellence 277 "Cognitive Interaction Technology" (CITEC) and Collaborative Research Center "Alignment in Communication,” SFB 673). 


\section{REFERENCES}

Amzica, F., and Lopes da Silva, F. H. (2011). "Cellular substrates of brain rhythms," in Niedermeyer's Electroencephalography: Basic Principles, Clinical Applications, and Related Fields, eds D. L. Schomer and F. H. Lopes da Silva (Philadelphia: Lippincott Williams \& Wilkins), 33-63.

Arnal, L. H., Wyart, V., and Giraud, A. L. (2011). Transitions in neural oscillations reflect prediction errors generated in audiovisual speech. Nat. Neurosci. 14, 797-801.

Babiloni, C., Babiloni, F., Carducci, F., Cincotti, F., Cocozza, G., Del Percio, C., Moretti, D. V., and Rossini, P. M. (2002). Human cortical electroencephalography (EEG) rhythms during the observation of simple aimless movements: a high-resolution EEG study. Neuroimage 17, 559-572.

Baker, S. N. (2007). Oscillatory interactions between sensorimotor cortex and the periphery. Curr. Opin. Neurobiol. 17, 649-655.

Barsalou, L. W. (2008). Grounded cognition. Annu. Rev. Psychol. 59, 617-645.

Başar, E., Başar-Eroglu, C., Karakas, S., and Schuermann, M. (1999). Are cognitive processes manifested in event-related gamma, alpha, theta and delta oscillations in the EEG? Neurosci. Lett. 259, 165-168.

Bastiaansen, M., and Hagoort, P. (2006). Oscillatory neuronal dynamics during language comprehension. Prog. Brain Res. 159, 179-196.

Bastiaansen, M., Magyari, L., and Hagoort, P. (2010). Syntactic unification operations are reflected in oscillatory dynamics during on-line sentence comprehension. J. Cogn. Neurosci. 22, 1333-1347.

Bastiaansen, M. C., van der Linden, M., Ter Keurs, M., Dijkstra, T., and Hagoort, P. (2005). Theta responses are involved in lexical-semantic retrieval during language processing. J. Cogn. Neurosci. 17, 530-541.

Berghoff, C., Weiss, S., and Mueller, H. M. (2005). "Processing figurative language: EEG-study with coherence analysis," in Proceedings of the 11th Annual Meeting of the Organization for of Human Brain Mapping, Toronto, 1576.

Bibbig, A., Traub, R. D., and Whittington, M. A. (2002). Long-range synchronization of gamma and beta oscillations and the plasticity of excitatory and inhibitory synapses: a network model. J. Neurophysiol. 88, 1634-1654.

Buzsáki, G. (2006). Rhythms of the Brain. New York: Oxford University Press.
Buzsáki, G., and Draguhn, A. (2004). Neuronal oscillations in cortical networks. Science 304, 1926-1929.

Davidson, D. J., and Indefrey, P. (2007). An inverse relation between eventrelated and time-frequency violation responses in sentence processing. Brain Res. 1158, 81-92.

de Lange, F. P., Jensen, O., Bauer, M., and Toni, I. (2008). Interactions between posterior gamma and frontal alpha/beta oscillations during imagined actions. Front. Hum. Neurosci. 2:7. doi:10.3389/neuro.09.007.2008

Donner, T. H., and Siegel, M. (2011). A framework for local cortical oscillation patterns. Trends Cogn. Sci. (Regul. Ed.) 15, 191-199.

Engel, A. K., and Fries, P. (2010). Betaband oscillations - signalling the status quo? Curr. Opin. Neurobiol. 20, 156-165.

Engel, A. K., Fries, P., and Singer, W. (2001). Dynamic predictions: oscillations and synchrony in top-down processing. Nat. Rev. Neurosci. 2, 704-716.

Fisher, A. E., Furlong, P. L., Seri, S., Adjamian, P., Witton, C., Baldeweg, T., Phillips, S., Walsh, R., Houghton, J. M., and Thai, N. J. (2008). Interhemispheric differences of spectral power in expressive language: a MEG study with clinical applications. Int. J. Psychophysiol. 68, 111-122.

Fries, P. (2005). A mechanism for cognitive dynamics: neuronal communication through neuronal coherence. Trends Cogn. Sci. (Regul. Ed.) 9, 474-480.

Fujioka, T., Trainor, L. J., Large, E. W., and Ross, B. (2009). Beta and gamma rhythms in human auditory cortex during musical beat processing. Ann. N. Y. Acad. Sci. 1169, 89-92.

Gilbertson, T., Lalo, E., Doyle, L., Di Lazzaro, V., Cioni, B., and Brown, P. (2005). Existing motor state is favored at the expense of new movement during 13-35 Hz oscillatory synchrony in the human corticospinal system. J. Neurosci. 25, 7771-7779.

Grabner, R. H., Brunner, C., Leeb, R., Neuper, C., and Pfurtscheller, G. (2007). Event-related EEG theta and alpha band oscillatory responses during language translation. Brain Res. Bull. 72, 57-65.

Gray, C. M., Koenig, P., Engel, A. K., and Singer, W. (1989). Oscillatory responses in cat visual cortex exhibit inter-columnar synchronization which reflects global stimulus properties. Nature 338, 334-337.

Haarmann, H. J., Cameron, K. A., and Ruchkin, D. S. (2002). Neural synchronization mediates on-line sentence processing: EEG coherence evidence from filler-gap constructions. Psychophysiology 39, 820-825.

Hanslmayr, S., Spitzer, B., and Baeuml, K. H. (2009). Brain oscillations dissociate between semantic and nonsemantic encoding of episodic memories. Cereb. Cortex 19, 1631-1640.

Hanslmayr, S., Staudigl, T., and Fellner, M. C. (2012). Oscillatory power decreases and long-term memory: the information via desynchronization hypothesis. Front. Hum. Neurosci. 6:74. doi:10.3389/fnhum.2012.00074

Hari, R., Forss, N., Avikainen, S., Kirveskari, E., Salenius, S., and Rizzolatti, G. (1998). Activation of human primary motor cortex during action observation: a neuromagnetic study. Proc. Natl. Acad. Sci. U.S.A. 95, 15061-15065.

Hipp, J. F., Engel, A. K., and Siegel, M. (2011). Oscillatory synchronization in large-scale cortical networks predicts perception. Neuron 69, 387-396.

Hirata, M., Koreeda, S., Sakihara, K., Kato, A., Yoshimine, T., and Yorifuji, S. (2007). Effects of the emotional connotations in words on the frontal areas - a spatially filtered MEG study. Neuroimage 35, 420-429.

Jarvelainen, J., Schurmann, M., and Hari, R. (2004). Activation of the human primary motor cortex during observation of tool use. Neuroimage 23, 187-192.

Jenkinson, N., and Brown, P. (2011). New insights into the relationship between dopamine, beta oscillations and motor function. Trends $\mathrm{Neu}$ rosci. 34, 611-618.

Jensen, O., and Colgin, L. L. (2007). Cross-frequency coupling between neuronal oscillations. Trends Cog. Sci. (Regul. Ed.) 11, 267-269.

Kim, J. S., and Chung, C. K. (2008). Language lateralization using MEG beta frequency desynchronization during auditory oddball stimulation with one-syllable words. Neuroimage 42, 1499-1507.

Klimesch, W. (1999). EEG alpha and theta oscillations reflect cognitive and memory performance: a review and analysis. Brain Res. Rev. 29, 169-195.

Klimesch, W., Doppelmayr, M., Wimmer, H., Gruber, W., Rohm, D., Schwaiger, J., and Hutzler, F. (2001). Alpha and beta band power changes in normal and dyslexic children. Clin. Neurophysiol. 112, 1186-1195.

Knyazeva, M. G., Fornari, E., Meuli, R., and Maeder, P. (2006). Interhemispheric integration at different spatial scales: the evidence from EEG coherence and FMRI. J. Neurophysiol. 96, 259-275.

Kopell, N., Ermentrout, G. B., Whittington, M. A., and Traub, R. D. (2000). Gamma rhythms and beta rhythms have different synchronization properties. Proc. Natl. Acad. Sci. U.S.A.97, 1867-1872.

Kopell, N., Kramer, M. A., Malerba, P., and Whittington, M. A. (2010). Are different rhythms good for different functions? Front. Hum. Neurosci. 4:187. doi:10.3389/fnhum.2010.00187

Kopell, N., Whittington, M. A., and Kramer, M. A. (2011). Neuronal assembly dynamics in the betal frequency range permits short-term memory. Proc. Natl. Acad. Sci. U.S.A. 108, 3779-3784.

Krause, C. M., Gronholm, P., Leinonen, A., Laine, M., Sakkinen, A. L., and Soderholm, C. (2006). Modality matters: the effects of stimulus modality on the $4-$ to $30-\mathrm{Hz}$ brain electric oscillations during a lexical decision task. Brain Res. 1110, 182-192.

Lachaux, J.-P., Rodriguez, E., Martinerie, J., and Varela, F. J. (1999). Measuring phase synchrony in brain signals. Hum. Brain Mapp. 8, 194-208.

Leiberg, S., Lutzenberger, W., and Kaiser, J. (2006). Effects of memory load on cortical oscillatory activity during auditory pattern working memory. Brain Res. 1120, 131-140.

Levy, R., and Goldman-Rakic, P. S. (2000). Segregation of working memory functions within the dorsolateral prefrontal cortex. Exp. Brain Res. 133, 23-32.

Lingner, T. (2005). Neue Ansätze zum maschinellen Lernen von Alignments. Diploma thesis, Bielefeld University (with Ulf Großekathoefer).

Luo, Y., Zhang, Y., Feng, X., and Zhou, X. (2010). Electroencephalogram oscillations differentiate semantic and prosodic processes during sentence reading. Neuroscience 169, 654-664.

Neuper, C., Wortz, M., and Pfurtscheller, G. (2006). ERD/ERS patterns reflecting sensorimotor activation and deactivation. Prog. Brain Res. 159, 211-222.

Nunez, P. L. (2000). Toward a quantitative description of large-scale neocortical dynamic function and EEG. Behav. Brain Sci. 23, 371-398; discussion 399-437.

Nunez, P. L., and Srinivasan, R. (2006). Electric Fields of the Brain: The Neurophysics of EEG. Oxford: Oxford University Press. 
Penolazzi, B., Spironelli, C., Vio, C., and Angrilli, A. (2010). Brain plasticity in developmental dyslexia after phonological treatment: a beta EEG band study. Behav. Brain Res. 209, 179-182.

Pfurtscheller, G., and Lopes da Silva, F. H. (2011). "EEG event-related desynchronization (ERD) and event-related synchronization (ERS)," in Niedermeyer's Electroencephalography: Basic Principles, Clinical Applications, and Related Fields, eds D. L. Schomer and F. H. Lopes da Silva (Philadelphia: Lippincott Williams \& Wilkins), 33-63.

Pfurtscheller, G., Stancak, A. J., and Edlinger, G. (1997). On the existence of different types of central beta rhythms below $30 \mathrm{~Hz}$. Electroencephalogr. Clin. Neurophysiol. 102, 316-325.

Pfurtscheller, G., Stancak, A. J., and Neuper, C. (1996). Post-movement beta synchronization. A correlate of an idling motor area? Electroencephalogr. Clin. Neurophysiol. 98, 281-293.

Pulvermueller, F. (2005). Brain mechanisms linking language and action. Nat. Rev. Neurosci. 6, 576-582.

Roopun, A. K., Middleton, S. J., Cunningham, M. O., LeBeau, F. E., Bibbig, A., Whittington, M. A., and Traub, R. D. (2006). A beta2-frequency $(20-30 \mathrm{~Hz})$ oscillation in non-synaptic networks of somatosensory cortex. Proc. Natl. Acad. Sci. U.S.A. 103, 15646-15650.

Schack, B., and Weiss, S. (2005). Quantification of phase synchronization phenomena and their importance for verbal memory processes. Biol. Cybern. 92, 275-287.
Scheeringa, R., Fries, P., Petersson, K. M., Oostenveld, R., Grothe, I., Norris, D. G., Hagoort, P., and Bastiaansen, M. C. M. (2011). Neuronal dynamics underlying high- and low-frequency EEG oscillations contribute independently to the human BOLD signal. Neuron 69, 572-583.

Shahin, A. J., Picton, T. W., and Miller, L. M. (2009). Brain oscillations during semantic evaluation of speech. Brain Cogn. 70, 259-266.

Siegel, M., Donner, T. H., and Engel, A. K. (2012). Spectral fingerprints of large-scale neuronal interactions. Nat. Rev. Neurosci. 13, 121-134.

Singer, W. (2009). Distributed processing and temporal codes in neuronal networks. Cogn. Neurodyn. 3, 189-196.

Singh, K. D., Barnes, G. R., Hillebrand, A., Forde, E. M., and Williams, A. L. (2002). Task-related changes in cortical synchronization are spatially coincident with the hemodynamic response. Neuroimage 16, 103-114.

Tallon-Baudry, C., Kreiter, A., and Bertrand, O. (1999). Sustained and transient oscillatory responses in the gamma and beta bands in a visual short-term memory task in humans. Vis. Neurosci. 16, 449-459.

van Ede, F., Jensen, O., and Maris, E. (2010). Tactile expectation modulates pre-stimulus beta-band oscillations in human sensorimotor cortex. Neuroimage 51, 867-876.

van Elk, M., van Schie, H. T., Zwaan, R. A., and Bekkering, H. (2010). The functional role of motor activation in language processing: motor cortical oscillations support lexicalsemantic retrieval. Neuroimage 50, 665-677. von der Malsburg, C., and Schneider, W. (1986). A neural cocktailparty processor. Biol. Cybern. 54 29-40.

von Stein, A., Chiang, C., and Koenig, P. (2000). Top-down processing mediated by interareal synchronization. Proc. Natl. Acad. Sci. U.S.A. 97, 14748-14753.

von Stein, A., Rappelsberger, P., Sarnthein, J., and Petsche, H. (1999). Synchronization between temporal and parietal cortex during multimodal object processing in man. Cereb. Cortex 9, 137-150.

von Stein, A., and Sarnthein, J. (2000). Different frequencies for different scales of cortical integration: from local gamma to long range alpha/theta synchronization. Int. J. Psychophysiol. 38 301-313.

Weiss, S., Berghoff, C., Rappelsberger, P., and Mueller, H. M. (2001) "Elektrophysiologische Hinweise zur Kategorisierung von Verben," in Tagungsband der 1. Jahrestagung der Gesellschaft fuer Aphasieforschung und -behandlung GAB, Bielefeld, 64

Weiss, S., and Jannek, D. (2007). "Neuronal coupling during the comprehension of concrete and abstract sentences," in Beitraege zur 8. Jahrestagung der Gesellschaft für Kognitionswissenschaft, Aachen.

Weiss, S., and Mueller, H. M. (2003). The contribution of EEG coherence to the investigation of language. Brain Lang. 85, 325-343.

Weiss, S., Mueller, H. M., Schack, B. King, J. W., Kutas, M., and Rappelsberger, P. (2005). Increased neuronal communication accompanying sentence comprehension. Int. J. Psychophysiol. 57, 129-141.
Weiss, S., and Rappelsberger, P. (1996). EEG coherence within the $13-18 \mathrm{~Hz}$ band as a correlate of a distinct lexical organization of concrete and abstract nouns in humans. Neurosci. Lett. 209, 17-20.

Weiss, S., and Rappelsberger, P. (1998). Left frontal EEG coherence reflects modality independent language processes. Brain Topogr. 11, 33-42.

Weiss, S., and Rappelsberger, P. (2000). Long-range EEG synchronization during word encoding correlates with successful memory performance. Brain Res. Cogn. Brain Res. 9, 299-312.

Conflict of Interest Statement: The authors declare that the research was conducted in the absence of any commercial or financial relationships that could be construed as a potential conflict of interest.

Received: 07 March 2012; accepted: 30 May 2012; published online: 25 June 2012.

Citation: Weiss $S$ and Mueller HM (2012) "Too many betas do not spoil the broth": the role of beta brain oscillations in language processing. Front. Psychology 3:201. doi: 10.3389/fpsyg.2012.00201

This article was submitted to Frontiers in Language Sciences, a specialty of Frontiers in Psychology.

Copyright (c) 2012 Weiss and Mueller. This is an open-access article distributed under the terms of the Creative Commons Attribution Non Commercial License, which permits non-commercial use, distribution, and reproduction in other forums, provided the original authors and source are credited. 